\title{
CHEMICAL, CLINICAL, AND IMMUNOLOGICAL STUDIES ON THE PRODUCTS OF HUMAN PLASMA FRACTIONATION.
}

\author{
XIX. A NOTE ON THE USE OF FIBRINOGEN \\ AND THROMBIN IN THE SURFACE \\ TRE.ATMENT OF BURNS 1,2,3 \\ BY CLINTON v. Z. HAWN, EDGAR A. BERING, JR., ${ }^{4}$ ORVILLE T. BAILEY, \\ AND S. HOWARD ARMSTRONG, JR. ${ }^{5}$ \\ (From the Departments of Pathology and Physical Chemistry, Harvard Medical School, Boston)
}

(Received for publication February 17, 1944)

When, in the early phases of the war, the number of burn casualties made the treatment of this group of lesions a problem of considerable importance, the need for an agent in the surface therapy of burns which would meet the 4 following criteria was pointed out to those engaged in the plasma fractionation program:

1. It should lack the deleterious effect on healing possessed by the conventional escharotics (1 to 3$)$.

2. It should possess properties of high stability and low bulk from the standpoint of transportation.

3. It should be susceptible of simple and speedy application.

4. It should possess requisite mechanical properties to permit immediate mobilization of casualties under field conditions.

At this time it became apparent that large quantities of purified human fibrinogen and thrombin were becoming available through the

\footnotetext{
1 This article has been released for publication by the Division of Publications of the Bureau of Medicine and Surgery of the United States Navy. The opinions or assertions contained herein are the private ones of the writers and are not to be construed as official or reflecting the views of the Navy Department or the Naval Service at large.

2 This work has been carried out under contract, recommended by the Committee on Medical Research, between the Office of Scientific Research and Development and Harvard University.

${ }^{3}$ This paper is Number 24 in the series, "Studies on Plasma Proteins," from the Harvard Medical School, Boston, Massachusetts, on products developed by the Department of Physical Chemistry from blood collected by the American Red Cross.

${ }^{4}$ Lieutenant, United States Naval Reserve.

${ }^{5}$ Welch Fellow in Internal Medicine of the National Research Council, Member, Society of Fellows, Harvard University, during the first year of these investigations.
}

fractionation of human plasma to prepare albumin for the armed forces $(4,5)$. Studies, therefore, were undertaken to develop from these proteins, which constitute important components in the natural mechanism for the protection of wounds, a dressing which would meet these specifications.

\section{THE HEALING PROCESS UNDER FIBRINOGEN- THROMBIN FILMS}

The initial phases of the work which were carried on both in animals and men were aimed at determining whether fibrinogen-thrombin mixtures, together with other substances as plasticizers, met the first of the specifications, namely, that they have no deleterious effect on the healing process.

Animal experiments. The nature of the skin surface of common laboratory animals is such that blistering and loss of serum do not follow a burn with the exception of such regions as between the toes. Thus, in setting up a standard experimental procedure for the study of healing, a mechanically denuded surface was emplored.

In guinea pigs weighing 350 to 450 grams, a central circular portion of skin and subcutaneous tissue, approximately $4 \mathrm{~cm}$. in diameter, was excised from the midportion of the back, leaving the denuded fascial covering of the lumbodorsal muscles as the presenting surface. Human fibrinogen and thrombin were applied to the denuded surfaces in various forms and in combination with plasticizers and sulfadiazine. Animals used for control purposes received identical wounds which were permitted to form their own natural scabs. These scabs showed a tendency to crack earlier and more frequently than 


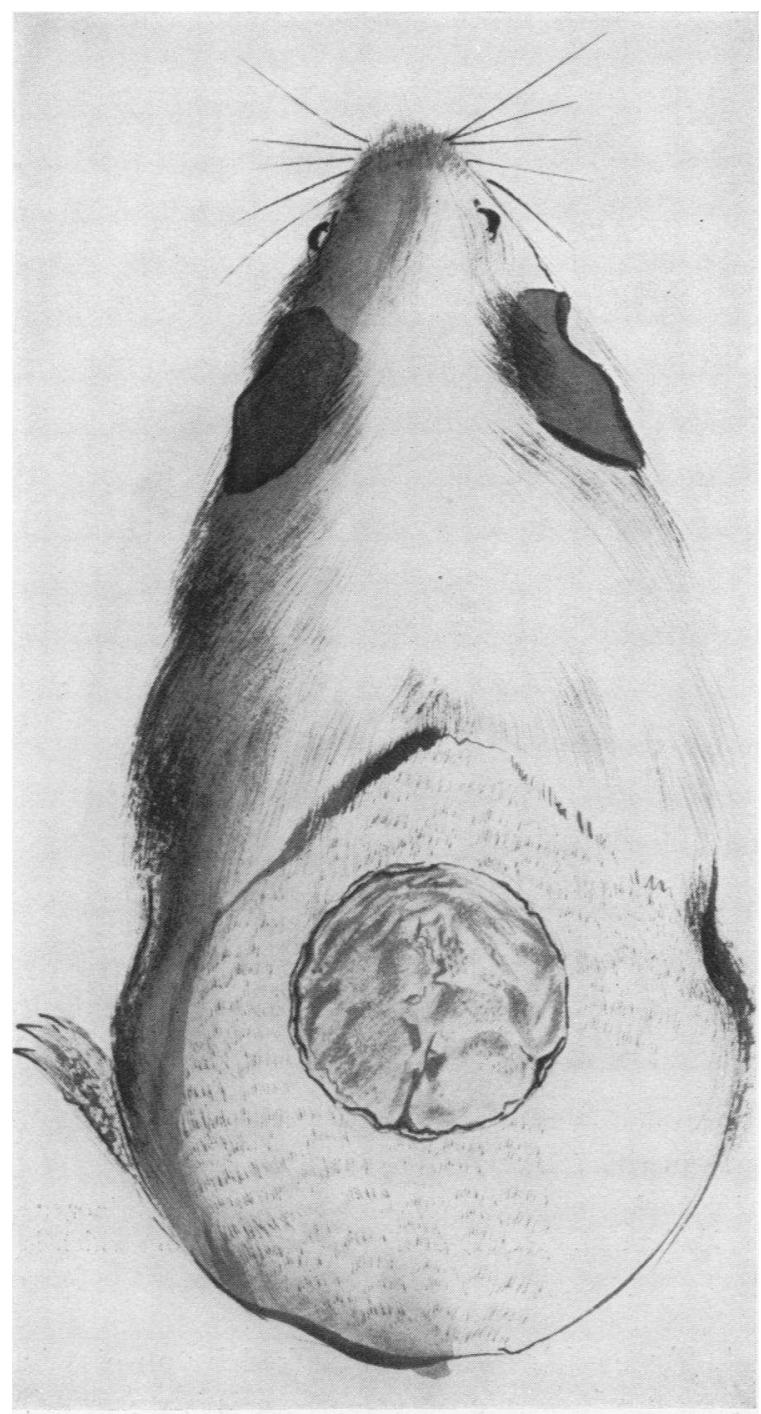

Fig. 1. Drawing of Guinea Pig 5 Days After the Application of Fibrinogen-Thrombin Mixture

The extent and placing of the denuded area used for experiments is indicated, as well as the appearance of the fibrinogen-thrombin eschar af ter 5 days.

did the applied films, with resultant secondary exudation.

In sections of wounds, 6 hours after the application of fibrinogen-thrombin mixtures, the applied film could be seen as resting on the tissue of the denuded surface and extending over the epidermal margins, thus providing an effective seal of the wound. Sections at 24 hours showed minimal hemorrhage and edema. Sections at 7 days revealed the repair process well under way. At the margins of the wound, the regenerating epithelium could be seen growing over the granulations and dissecting beneath the film (Figures 2 and 3). In instances where carbon particles had been incorporated in the films, only rarely was the carbon found in the underlying granulation tissue. Thus, the film remained almost entirely unorganized.

In the control series of untreated animals, the natural scabs showed a tendency to crack earlier and more frequently than did the applied films, with resultant secondary exudation. In general, histological sequences similar to those described in treated animals were observed. Although hemorrhage and edema were more frequent in the early stages, sections at 7 days demonstrated approximately the same amount of clear granulation tissue and the same amount of epithelialization at the wound margins.

These histological studies showed that the applied films were essentially inert. They evoked no inflammatory response in the denuded tissues. They fulfilled the function of a natural eschar in protecting the underlying wound during the repair process and permitting epithelialization to proceed at a normal rate.

Human studies. Certain of the fibrinogenthrombin mixtures studied on guinea pigs were applied to a small group of burns, both of second and third degree, in human patients. Clinical observations served to indicate that in man as well as in guinea pigs there was no deleterious effect on the healing process. ${ }^{6}$

In the controlled study on the healing of skin graft donor sites, Cannon and Cope (1) reported a more rapid rate of epithelialization under fibrinogen-thrombin mixtures than under certain escharotics.

\section{CLINICAL USE OF FIBRINOGEN-THROMBIN FILMS}

In the studies recorded above, the films were made by clotting various types of mixtures of fibrinogen and thrombin on the site of injury. It became obvious from clinical experience with human burns that this procedure was too cumbersome and yielded mechanical properties unsuitable for use in the field. The development of

${ }^{6} \mathrm{We}$ are indebted to Dr. Charles C. Lund, Dr. E. D. Churchill, Dr. Oliver Cope, Dr. Henry Marble, and Dr. Richard Wallace for their clinical material put at our disposal and for their aid and advice in the study of these patients. 


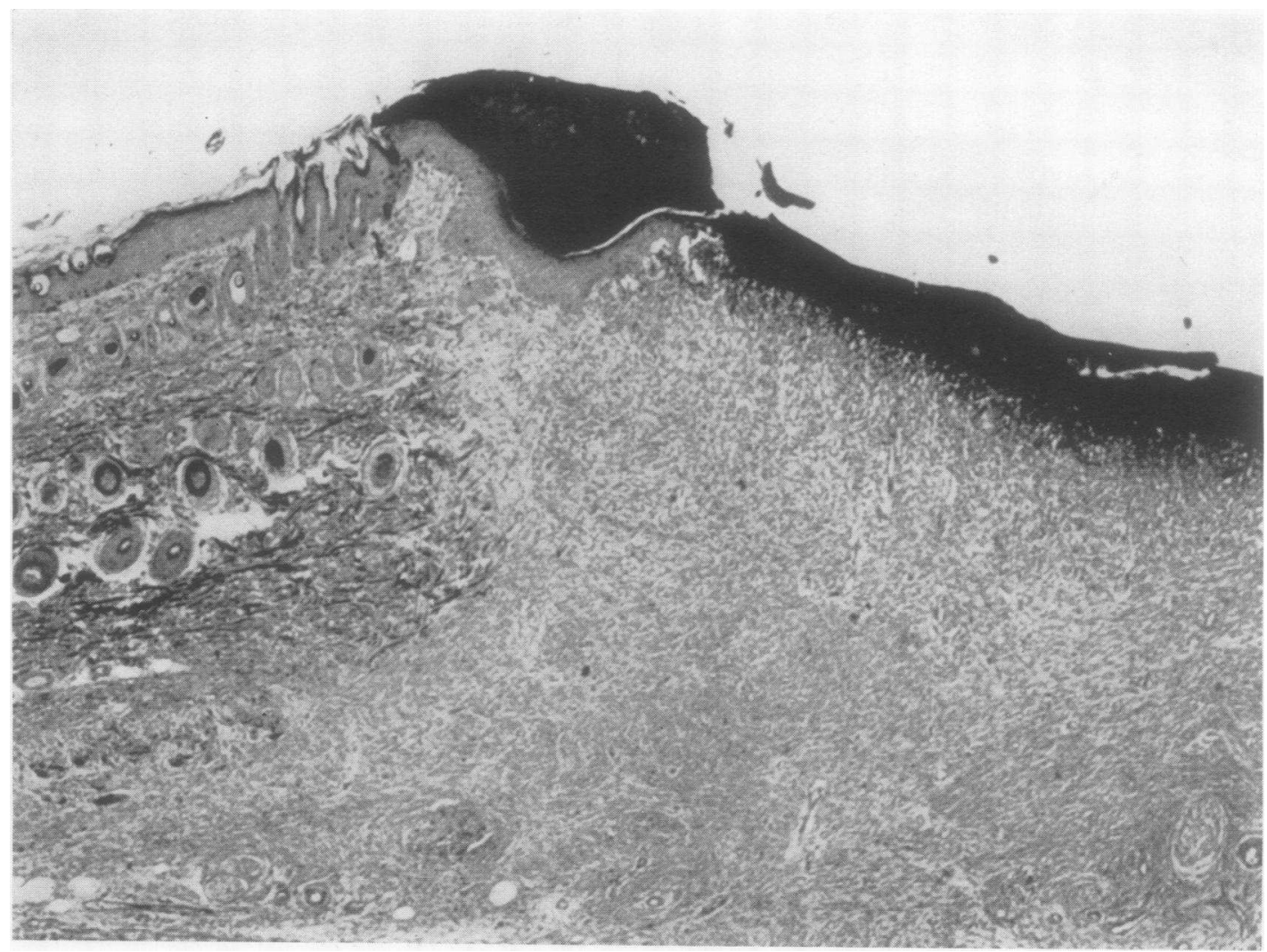

Fig. 2. Low Power Photomicrograph of a Denuded Surface Covered by Fibrinogen-Thrombin Mixture for 7 Days

In the central portion (at the right of the illustration), there is granulation tissue covered by dark staining fibrinogenthrombin mixture. The normal skin is shown on the left of the illustration. At the center is the epithelium which is extending over the defect and elevating the eschar.

preformed fibrin films of a wide range of properties by Ferry and Morrison $(6,7)$ opened the possibility ${ }^{-}$of preparing a fibrinogen-thrombin dressing which would combine the lack of deleterious effect on the healing process with the properties considered above, namely, simplicity and speed in application and a range in mechanical properties permitting adaptation to many types of field conditions.

Films exhibiting high resistance to fibrinolysis proved most suitable for use in burns. Of these the following types (6) have been made available to us:

1. Type $P$ : plain fibrin film.

2. Type F : fibrin film backed by an elastic cotton fabric similar in structure to "Ace Bandage."

3. Type W: fibrin film backed on one side by a waterproof plastic.
4. Type WF: fibrin film backed by an elastic cotton fabric whose outer surface is waterproof.

Preliminary trials of certain of these films have been made on a small group of burns at the Boston City Hospital. ${ }^{7}$ These cases are presented in Table I. There are included both second and third degree burns of arms, legs, and trunk. On each patient, areas were treated with fibrin films and controlled by equivalent areas treated with vaseline impregnated gauze. In all cases, the dressings were quickly and easily applied. The relief of pain was rapid and consistent. In the case of the second degree burns, healing under the films was as rapid as the control areas in all instances. The fibrin films became lightly ad-

${ }^{7} \mathrm{We}$ are indebted to Dr. Charles C. Lund and Dr. Stanley M. Levenson of the Burns Assignment of the Boston City Hospital for their clinical cooperation. 
herent after application and so remained until epithelialization was complete, when the films would become dry and fall off. Dr. Lund, of the Burns Assignment, has stated that in second degree burns, "healing took place as rapidly as with any method known to date" (8).

In only one instance of second degree burns was there any infection; that was a staphylococcus albus infection which was not serious enough to delay healing.

In the third degree burns, the films appeared to be superior to the gauze ointment dressing used in control areas in that the film being only lightly adherent could be removed without pain or tearing underlying granulations, thus facilitating dressing in preparation of a sloughing area for grafting. When used over third degree burns, a moderate amount of fibrinolysis has been present after about the tenth day, which has been about the time when removal of the original dressing for study of demarcation of the slough is indicated. The fibrin films were not limited to the initial dressing but also used as secondary dressings.

\section{COMMENT}

Not only in the general management of the burned patient but also in the therapy of the injured surface, physiological and bacteriological considerations arise which are to a great measure independent of the actual material chosen for application, provided the material does not interfere with the normal process of repair. A large body of recent work has yielded striking advances in the elucidation of these considerations. To this aspect of the burn problem, the current observations made no contribution. It is essential, however, that the material for surface application be adaptable to the conditions of treatment which emerge from considerations of physiology and bacteriology.

In addition to lack of deleterious effect on the healing process, the fibrin films used in this study are adaptable to many programs of surface

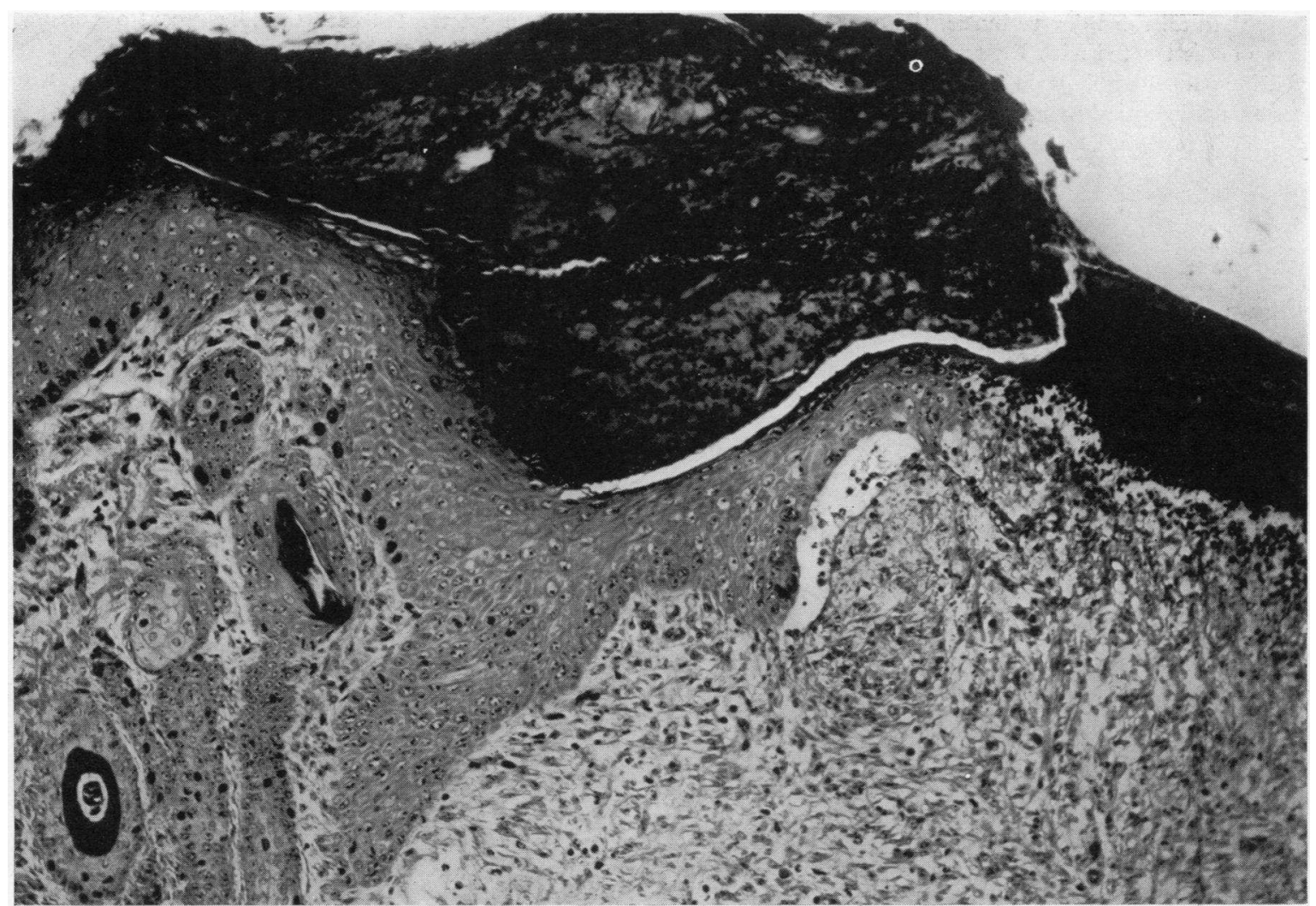

Fig. 3. Higher Power Photomicrograph to Show the Extension of the Epithelium Under the Eschar 
TABLE I

Cases of second and third degree burn surfaces treated with fibrin film

\begin{tabular}{c|c|c|c|c|}
\hline \hline Case No. & Type film & Healing time & Infection \\
\cline { 3 - 5 } & $\begin{array}{c}\text { Films } \\
\text { (days) }\end{array}$ & $\begin{array}{c}\text { Control } \\
\text { (days) }\end{array}$ & $\begin{array}{c}\text { Debridement } \\
\text { before } \\
\text { dressing } \\
\text { film }\end{array}$ \\
\hline
\end{tabular}

Second Degree Burns

\begin{tabular}{|c|c|c|c|c|c|c|}
\hline $\begin{array}{l}27 \\
29 \\
30 \\
33 \\
35 \\
36 \\
37\end{array}$ & $\begin{array}{l}\mathrm{P} \\
\mathrm{P} \\
\mathrm{P} \\
\mathrm{P} \\
\mathrm{P} \\
\mathrm{P} \\
\mathrm{W}\end{array}$ & $\begin{array}{r}4 \\
6 \\
4 \\
9 \\
6 \\
5 \\
10 \\
10\end{array}$ & $\begin{array}{r}9^{*} \\
6^{*} \\
4^{*} \\
9^{*} \\
6^{*} \\
5^{*} \\
10^{*} \\
*^{*}\end{array}$ & $\begin{array}{c}\text { None } \\
\text { Staph. albus } \\
\text { None } \\
\text { None } \\
\text { None } \\
\text { None } \\
\text { None } \\
\text { None }\end{array}$ & $\begin{array}{l}* * * * \\
\text { None } \\
* * * * \\
* * * * \\
\text { None } \\
\text { None } \\
\text { None } \\
\text { None }\end{array}$ & $\begin{array}{l}0 \\
0 \\
0 \\
0 \\
0 \\
0 \\
0 \\
0\end{array}$ \\
\hline \multicolumn{7}{|c|}{ Third Degree Burns } \\
\hline 31 & $\mathrm{P}$ & $\begin{array}{l}\text { Slough demarcated } \\
\text { in } 5 \text { days } \\
\text { Slough well demarcated } \\
\text { in } 16 \text { days } \\
\text { Slough well demarcated } \\
\text { in } 16 \text { days }\end{array}$ & $\begin{array}{l}* * * \\
* * *\end{array}$ & $\begin{array}{l}\text { Pyocyan, } \beta \text {-Strept., } \\
\text { Staph. aureus } \\
\alpha \text { - and } \beta \text {-Strept., } \\
\text { Staph. aureus } \\
\text { Not reported }\end{array}$ & $\begin{array}{c}\text { None } \\
\text { None } \\
* * * *\end{array}$ & $\begin{array}{l}3 \text { per cent in } \\
6 \text { days } \\
40 \text { to } 60 \text { per cent } \\
\text { in } 16 \text { days } \\
\text { Complete in } \\
12 \text { days }\end{array}$ \\
\hline
\end{tabular}

* Vaseline or boric ointment gauze.

** Control area covered with a cast which was not removed until after the sixteenth day.

*** In all third degree burns, the control areas were similar to the areas treated with the film except one instance where areas treated with Bentonite had an eschar-like crust which was removed with great pain. The removal of the vaseline gauze dressings on control areas was uniformly more difficult and painful than the removal of the films which was as a rule entirely without pain.

**** Loose skin removed, cleansed with soap and water, followed by saline irrigation.

therapy. Thus, either an open or closed dressing may be attained depending on the degree of adhesiveness of the film chosen and whether or not it be perforated. Again, films may be used without pressure, either in conjunction with a Koch pressure dressing (11) or beneath a case $(10,11)$. In point of fact, the Type WF film was developed in order to provide a speedy low bulk waterproof first aid dressing for the field wherein moderate pressure could be attained by reason of the elastic fabric backing.

In the light of recent studies (12), the evaluation of fibrin films has proceeded to date with bacteriostatic conditions uncontrolled. Sulfonamide drugs, penicillin, urea, methionine, or other substances of local value, may well be incorporated in films. ${ }^{8}$

${ }^{8}$ In that recent evidence of Schmelkes and his coworkers (13) has suggested that sulfonamides buffered at high $\mathrm{pH}$ have a definite local action in the prevention of infection, further investigations are being carried out on films con-
Among the wide variety of films which have been employed on burned surfaces both by direct application and in the preformed state $(2,14$ to $17)$, the only one in which the proteins involved in the natural coagulation mechanism were used is the fibrin membrane of Macfarlane (18). Whereas from the standpoint of healing, the membranes prepared by this worker were described as satisfactory, 3 drawbacks were listed. From the standpoint of mechanical properties, the membranes became brittle on drying and occasionally showed a tendency to lysis within 24 hours of application to a burned area. Their instability even under refrigeration did not permit transportation for field use. The method used for their manufacture involved the loss of the other parts of plasma, leading the author to remark, "It would probably be more economical

taining a high percentage of sodium sulfadiazine by Dr. William Andrus of the New York Hospital in a controlled series of experimental human burns. 
to transfuse the patient with the plasma required to make the membrane."

The fibrin films we have used do not lead to the difficulties encountered by Macfarlane, in that when applied they remain flexible, they exhibit minimal tendency to fibrinolysis; packaged in sterile fashion they remain stable at room temperature for indefinite periods; the other components of the plasma from which they are manufactured are separately processed for their various therapeutic functions (4) which leaves the albumin available to "transfuse the patient."

It should be emphasized, in view of the reports of satisfactory use of many types of surface agents in burns, that a well-controlled comparative study is necessary to establish the respective merits of the various substances, from the standpoint of both civilian and military use (3). The observations here presented suggest that fibrin film can be adapted to the specifications, set forth at the initiation of this study, for the surface therapy of burns under certain field conditions.

\section{SUMMARY}

Observations of surgically denuded areas of animals and burns on humans are presented which suggest that human fibrinogen and thrombin mixtures have no deleterious effect on normal processes of repair. The use of preformed fibrin films, prepared from the proteins involved in the natural coagulation mechanism, is described in a small series of second and third degree burns. Such films are capable of adaptation to many programs of surface therapy. It is suggested that such films, particularly in the form of roll bandages, might prove a highly expedient fibrinogen-thrombin dressing for burns in the field, owing to simplicity and speed from the standpoint of application, and to lack of bulk from the standpoint of transportation.

\section{BIBLIOGRAPHY}

1. Cannon, B., and Cope, O., Rate of epithelial regeneration. A clinical method of measurement, and the effect of various agents recommended in the treatment of burns. Ann. Surg., 1943, 117, 85.

2. Skinner, H. G., and Waud, R. A., Plastic film treat- ment of experimental burns. Canad. M. A. J., $1943,48,13$.

3. Clowes, G. H. A., Jr., Lund, C. C., and Levenson, S. M., The surface treatment of burns. Ann. Surg., $1943,118,761$.

4. Cohn, E. J., Oncley, J. L., Strong, L. E., Hughes, W. L., Jr., and Armstrong, S. H., Jr., Chemical, clinical, and immunological studies on the products of human plasma fractionation. I. The characterization of the protein fractions of human plasma. J. Clin. Invest., 1944, 23, 417.

5. Edsall, J. T., Ferry, R. M., and Armstrong, S. H., Jr., Chemical, clinical, and immunological studies on the products of human plasma fractionation. XV. The proteins concerned in the blood coagulation mechanism. J. Clin. Invest., 1944, 23, 557.

6. Ferry, J. D., and Morrison, P. R., Chemical, clinical, and immunological studies on the products of human plasma fractionation. XVI. Fibrin clots, fibrin films, and fibrinogen plastics. J. Clin. Invest., 1944, 23, 566.

7. Morrison, P. R., and Singer, M., Chemical, clinical, and immunological studies on the products of human plasma fractionation. XVII. Note on the absorption rates of fibrin films in tissue. J. Clin. Invest., 1944, 23, 573.

8. Lund, C. C., Personal communication.

9. Allen, H. S., and Koch, S. L., The treatment of patients with severe burns. Surg., Gynec., and Obst., 1942, 74, 914.

10. Glenn, W. W. L., Gilbert, H. H., and Drinker, C. $\mathrm{K}$., The treatment of burns by the closed-plaster method, with certain physiological considerations implicit in the success of this technique. J. Clin. Invest., 1943, 22, 609.

11. Levenson, S. M., and Lund, C. C., The treatment of burns of the extremities. J. A. M. A., 1943, 123, 272.

12. Meleney, F. L., The study of the prevention of infection in contaminated accidental wounds, compound fractures and burns. Ann. Surg., 1943, 118, 171.

13. Schmelkes, F. C., Wyss, O., Marks, H. C., Ludwig, B. J., and Strandskov, F. B., Mechanism of sulfonamide action; acidic dissociation and antibacterial effect. Proc. Soc. Exper. Biol. and Med., 1942, 50, 145.

14. Pickrell, K. L., A new treatment for burns; preliminary report. Bull. Johns Hopkins Hosp., 1941, 69, 217.

15. Pickrell, K. L., Sulfonamide film for use as surgical dressing; preliminary report. Bull. Johns Hopkins Hosp., 1942, 71, 304.

16. Andrus, W. DeW., Nickel, W. F., and Schmelkes, F. C., Treatment of burns with chemotherapeutic membranes. Arch. Surg., 1943, 46, 1.

17. Pendleton, R. C., The paraffin wax open air treatment of burns. J. A. M. A., 1943, 122, 414.

18. Macfarlane, R. G., Human fibrin as dressing for burns. Brit. M. J., 1943, 2, 541. 